\title{
Coaches and Teammates as Social Agents for Collegiate Athletes' Basic Psychological Need Satisfaction
}

\author{
Johannes Raabe \\ University of Tübingen \\ Rebecca A. Zakrajsek \\ University of Tennessee
}

\begin{abstract}
Teammates and coaches might be considered two of the most significant sources of social interactions for athletes. Deci and Ryan's (2000) self-determination theory offers a motivational framework that can be used to understand the quality of relationships within sport. Given the positive outcomes associated with fostering basic psychological need satisfaction (e.g., optimal social functioning, well-being, and self-development) researchers have been interested in understanding how athletes' perceptions of competence, autonomy, and relatedness can be nurtured. The purpose of the current study was to assess: (a) if there was a difference between participants' perceptions of their coaches' and teammates' influence on their basic psychological need satisfaction, (b) potential differences between participants' perceptions regarding the impact of coaches and teammates on their basic psychological need satisfaction in interactive and coactive sports, and (c) whether coaches' and teammates' influence on athletes' basic psychological need fulfillment affected participants' perception of, and satisfaction with, individual and team performance. 362 National Collegiate Athletic Association Division I student-athletes ( 226 female and 136 male; $M_{a g e}=19.36 ; S D=2.65$ ) from four different sports (i.e., track and field/cross country, soccer, basketball, and tennis) participated in the study. Results showed that while peers had a significantly more positive influence on individuals' basic psychological need satisfaction than coaches, it was the need fulfillment from coaches that predicted athletes' perceptions of, and satisfaction with, performance.
\end{abstract}

Keywords: self-determination theory, coaching, NCAA, motivation

\footnotetext{
Raabe is with the Department of Sport Psychology and Research Methods, University of Tübingen, Tübingen, Germany. Zakrajsek is with the Department of Kinesiology, Recreation, and Sport Studies, University of Tennessee, Knoxville, Tennessee. Address author correspondence to Johannes Raabe at johannes.raabe@ifs.uni-tuebingen.de.
} 
Within elite sport, athletes spend significant time around their coaches and peers (Froyen \& Pensgaard, 2014). For example, individuals competing at the National Collegiate Athletic Association (NCAA) Division I level typically devote four hours per day and 20 hours per week to athletically related activities (NCAA, 2014). The time student-athletes are in their sport environment becomes even more significant when considering these numbers are frequently surpassed by voluntary commitments. Collegiate athletics has become a year-round activity in which football players reported spending an average of 44.8 hours a week practicing, playing, or training for their sport (Wolverton, 2008). Given this information, teammates and coaches might be considered two of the most significant sources of social interactions and connections in the lives of athletes.

Researchers have suggested that athletes depend on coaches for their physical and psychological development (Poczwardowski, Barott, \& Henschen, 2002), which directly influences their satisfaction (Chelladurai, 1993), persistence (Pelletier, Fortier, Vallerand, \& Briere, 2001), and ultimately success in competition (Jowett \& Cockerill, 2003). Furthermore, athletes often view coaches as mentors and even parental figures (Gould, Dieffenbach, \& Moffett, 2002; Jowett \& Cockerill, 2003). This may stem from the fact that coaches are typically in charge of organizing, educating, advising, and supervising athletes on the teams they work with (Keegan, Spray, Harwood, \& Lavallee, 2010). As such, the coach-athlete relationship is one of the most influential factors determining athletes' experience (Mageau \& Vallerand, 2003) and plays an integral part in athletes' and sport teams' success. However, peer interactions have also been found to be formative for important outcomes related to athletes' participation such as motivation, confidence in ability, performance, coping, interpersonal development, social functioning, enjoyment, and well-being (Evans, Eys, \& Wolf, 2013; Mack et al., 2011). Because interactions with coaches and teammates influence athletes' thoughts, feelings, and behaviors (Vallerand \& Losier, 1999) the quality of these relationships would seem to be a relevant consideration in the development of athletes' performance, well-being, and satisfaction.

Self-determination theory (Deci \& Ryan, 2000) is a motivational framework that can be used to understand the quality of relationships within sport. Deci and Ryan (2000) offer an understanding of the complex and dynamic nuances of motivation (e.g., the different types of autonomous and controlled motivation) and the social conditions that either support or undermine optimal functioning. This framework has received increasing consideration in the sport context and has been used to investigate athletes' motivation (e.g., Hollembeak \& Amorose, 2005; Joesaar, Hein, \& Hagger, 2011), well-being (e.g., Gagne, 2003; Mack et al., 2011), and return to sport from injury (e.g., Podlog \& Dionigi, 2010). According to selfdetermination theory, social interactions that promote individuals' satisfaction of their innate basic psychological needs (i.e., competence, autonomy, and relatedness) contribute to optimal social functioning, well-being, and self-development (Gagne, 2003; Mack et al., 2011). The need for competence stems from the desire to be an effective agent within the environment. It is the desire to feel confident in one's ability to perform successfully in a given setting and situation. Autonomy entails the need to have meaningful choice and input in decisions. It is also the ability to act in accordance with one's values and be in charge of personal actions. Finally, relatedness is the need to feel valued and accepted within the environment. This 
means having a role within a group that is comfortable while feeling securely connected with other members.

Given the positive outcomes associated with fostering basic psychological need satisfaction (e.g., optimal social functioning, well-being, and self-development) researchers have been interested in understanding how athletes' perceptions of competence, autonomy, and relatedness can be nurtured. In particular, researchers have investigated the role of social agents in the development of these perceptions; both coaches (e.g., Amorose \& Anderson-Butcher, 2007; Hollembeak \& Amorose, 2005) and peers (e.g., Joesaar et al., 2011; Kipp \& Weiss, 2013) have been found to significantly influence athletes' basic psychological need satisfaction. Nevertheless, only a few researchers have explored the influence of coaches and teammates simultaneously (e.g., Blanchard, Amiot, Perreault, Vallerand, \& Provencher, 2009; Kipp \& Weiss, 2013).

Kipp and Weiss (2013) examined how various coach behaviors (e.g., mastery/ autonomy support and controlling behaviors) and teammate behaviors (e.g., quality of friendship) influenced adolescent female gymnasts' (10-17 years of age) need fulfillment. Coach behaviors were associated with athletes' perceptions of autonomy and teammate behaviors primarily affected perceptions of competence. Similarly, Blanchard et al. (2009) studied how coaching styles and team cohesion influenced Canadian male and female basketball players' (playing at a 12th grade level) perceptions of competence, autonomy, and relatedness. The researchers concluded that coaches' controlling interpersonal style predominantly affected athletes' fulfillment of autonomy, but not competence and relatedness. Simultaneously, team cohesion was associated with satisfaction of all three basic psychological needs. From this literature, it appears that various coach and teammate behaviors do influence need fulfillment. However, researchers have not directly compared the magnitude of coaches' and teammates' influence and, thus, the question yet to be addressed is: Between coaches and teammates, who has a stronger influence on athletes' perceptions of competence, autonomy, and relatedness? Assessing this potential difference would make sense with participants at the NCAA Division I level, given the significant amount of time coaches and teammates spend with each other in and out of the sport environment. Accordingly, the primary purpose of this exploratory study was to assess if there was a difference between collegiate athletes' perceptions of how their coaches and teammates influence their basic psychological need satisfaction. Gaining an understanding of this difference provides foundational information about the potential positive and negative influence of these two social agents on athletes' basic psychological needs satisfaction. Knowing this information can emphasize areas of strengths and areas for improvements (i.e., what particular needs each social agent might focus on improving).

Furthermore, when exploring social influences within sport it is important to consider the unique context and demands of the environment (Vallerand \& Losier, 1999). For example, athletes often compete as part of a team (e.g., at the NCAA Division I level all athletes compete on teams regardless of the nature of their sport); however, these teams can be interactive, which typically requires team members to coordinate their movements and work with one another (e.g., basketball or soccer) or coactive in that athletes compete individually but strive toward a common goal (e.g., cross-country or tennis; Weinberg \& Gould, 2011). Researchers have explored basic psychological need satisfaction within both 
interactive (e.g., Joesaar et al., 2011; Kipp \& Weiss, 2013) and coactive sports (e.g., Gagne, 2003; Gillet et al., 2009) and highlighted the importance of peer influences in each setting. While a limited number of studies included participants from multiple types of sports (e.g., Amorose \& Anderson-Butcher, 2007; Hollembeak \& Amorose, 2005), these endeavors did not assess potential differences in perceptions of competence, autonomy, and relatedness between interactive and coactive sport participants. An exception was the work by Stults-Kolehmainen, Gilson, and Abolt (2013) who found that collegiate athletes in team-oriented (i.e., interactive) sports reported higher levels of relatedness compared with athletes in individual-oriented (i.e., coactive) sports. However, Stults-Kolehmainen et al. (2013) only focused on relatedness and, consequently, did not explore if perceptions of competence and autonomy differed between athletes competing in different types of sport. In addition, no researchers have compared coaches' and teammates' influence on need fulfillment between types of sport. Consequently, the second purpose of the current study was to investigate potential differences between collegiate athletes' perceptions regarding the impact of coaches and teammates on their satisfaction of competence, autonomy, and relatedness in interactive and coactive sports. Such potential differences can help to identify the type of team structure (i.e., interactive or coactive) that appears to be more beneficial for athletes' need satisfaction. This allows researchers to subsequently explore specific characteristics of the optimal team structure and use that information to foster interactions that nurture a need-fulfilling motivational climate for athletes in both interactive and coactive environments.

Finally, previous endeavors comparing the influence of coaches' and teammates' behaviors on athletes' basic psychological need satisfaction simultaneously were primarily conducted with youth sport populations (e.g., Blanchard et al., 2009; Kipp \& Weiss, 2013); thus, not accounting for the challenges of the NCAA Division I environment, which places individuals in the unique situation of balancing the roles of student and athlete (Street, 1999). Not only do these student-athletes face the challenges of nonathletes (e.g., social adjustment, career exploration, intellectual growth), but they are also asked to practice and compete at an elite level in their sport (Watt \& Moore, 2001) with significant pressure to perform and achieve desired outcomes (Wrisberg \& Johnson, 2002). Gillet and colleagues (2009) studied a sample of national tennis players in France (13-14 years of age) and found performance directly influenced perceptions of competence, autonomy, and relatedness. Specifically, an increase in performance enhanced the satisfaction of all three basic psychological needs. Given this finding, it would seem worthwhile to consider if levels of competence, autonomy, and relatedness in turn also directly impact performance. Thus, the current study's third purpose was to assess whether coaches' and teammates' influence on athletes' basic psychological need fulfillment affected participants' perception of, and satisfaction with, individual and team performance. Despite the various benefits for nurturing athletes' perceptions of competence, autonomy, and relatedness (e.g., well-being; Gagne, 2003) Mageau and Vallerand (2003) suggest that many coaches do not effectively and sufficiently engage in behaviors that nurture such need satisfaction. This may in part be due to the belief that a focus on need fulfillment is incompatible with competitive success. Therefore, understanding the possible relationship between athletes' perceptions of competence, autonomy, and relatedness and performance 
can potentially nurture coaches' buy-in for fostering need-supportive interactions with the athletes they work.

\section{Methods}

\section{Participants}

A total of 362 NCAA Division I student-athletes participated in this study; 226 $(62.4 \%)$ were female and $136(37.6 \%)$ were male. Participants self-identified as White/Caucasian $(n=241 ; 67 \%)$, African-American $(n=63 ; 17 \%)$, Hispanic/ Latino $(n=25 ; 6.9 \%)$, Asian/Pacific Islander $(n=14 ; 3.9 \%)$, and Other $(n=$ $13 ; 3.6 \%)$. These individuals were between 18 and 24 years old $(M=19.36 ; S D$ $=2.65)$ and represented a mix of freshmen $(n=120 ; 33.1 \%)$, sophomores $(n=$ $83 ; 22.9 \%)$, juniors $(n=83 ; 22.9 \%)$, and seniors $(n=71 ; 21.1 \%)$. A total of 235 participants $(64.9 \%)$ were on athletic scholarship. Participants competed in track and field/cross country $(n=202 ; 58.8 \%)$, soccer $(n=62 ; 17.2 \%)$, basketball $(n=$ $51 ; 14.2 \%)$, and tennis $(n=47 ; 13 \%)$. Finally, athletes had been members of their current collegiate team for an average of 2.63 seasons $(S D=1.95)$.

\section{Procedures}

Upon the university's Institutional Review Board approval, the head coaches of all women's and men's NCAA Division I athletic teams for the sports of basketball, soccer, tennis, and track and field/cross country were contacted via e-mail, provided with information about the study, and asked to forward the link for the online survey to their student-athletes. This particular population (i.e., NCAA Division I) was selected due to the elite status of the competitive level and the associated pressures to achieve outcome goals (Wrisberg \& Johnson, 2002). In addition, the specific sports were chosen to provide a mix between coactive and interactive teams to address the study's second objective. Contact information for head coaches $(N=$ 2184) was gathered from their respective athletic programs' websites, where e-mail addresses are available to the public on the staff directory. Student-athletes who accessed the survey link were invited to participate, provided with information about the project, and informed that their involvement was voluntary and anonymous. A second e-mail was sent to the NCAA Division I head coaches approximately oneweek later reminding them to forward the link to their student-athletes in an effort to increase participation rate. Student-athletes were instructed not to complete the survey if they had already done so.

\section{Instrumentation}

The online survey included: (a) a set of demographic questions and (b) two modified versions of the Basic Psychological Needs Scale (BPNS; Deci, Connell, \& Ryan, 1989). Demographic questions included participants' gender, age, race, academic standing, number of seasons on their current team, and scholarship status. In addition, participants rated their perception of, and satisfaction with, individual and team performance on a Likert-type scale from 1 (very poor) to 10 (very good) and 1 (not at all satisfied) to 10 (very satisfied), respectively. Such self-report measures 
for performance have previously been employed by researchers within sport psychology (e.g., Zakrajsek, Abildso, Hurst, \& Watson, 2007).

BPNS. The BPNS is a 21-item instrument that belongs to a family of scales aimed at assessing individuals' perceptions of competence (6 items), autonomy (7 items), and relatedness ( 8 items). Two separate versions of the BPNS were used in this study; one for coaches' and one for teammates' direct influence on need fulfillment. For the purpose of the study the stem of the scale was changed from "Feelings I have" to "When I do sport...." Then, individual items were slightly modified to make the questions more relevant for assessing athletes' perceptions of their coaches' and teammates' influence on basic psychological need satisfaction during sport participation. For example, within the competency subscale, "Often, I do not feel very competent" was changed to "Often, my coaches do not make me feel very competent in my sport" and "Often, my teammates do not make me feel very competent in my sport." Subscale items for autonomy (e.g., "My coaches/teammates do not give me much opportunity to decide for myself how to go about my sport") and relatedness ("My coaches/teammates care about me") included similar modifications. Adjustments did not alter the meaning of individual items. Similar revisions have recently been performed successfully by researchers within sport psychology (e.g., Long, Readdy, \& Raabe, 2014; Readdy, Raabe, \& Harding, 2014). For example, Readdy et al. (2014) modified the work-related version of the scale to measure the influence of an extrinsic reward program on NCAA Division I football players' basic psychological need satisfaction, but did not assess the influence of social agents. Long et al. (2014) used the same scale in a nonsport population to measure firefighters exercise behavior and modified the stem to "When I engage in work-related exercise...." Items within each subscale are rated using a Likert-type scale from 1 (not at all true) to 7 (very true). Baard, Deci, and Ryan (2004) showed evidence of the instrument's validity with a confirmatory factor analysis that supported the structure and demonstrated the discriminant validity of the different basic psychological needs. In addition, the scale's internal consistency reliability (i.e., alpha coefficients) was above .70 (Baard et al., 2004). Finally, a test-retest reliability of .80 indicated temporal stability (Baard et al., 2004).

\section{Data Analysis}

To address the first purpose of the study, a paired sample $t$ test was used to assess potential differences between collegiate athletes' perceptions of their coaches' and teammates' influence on their basic psychological need satisfaction. To address the second purpose of the study, a Multivariate Analysis of Variance (MANOVA) was conducted to investigate potential differences between collegiate athletes' perceptions regarding the impact of coaches and teammates on their satisfaction of competence, autonomy, and relatedness in interactive (i.e., basketball and soccer; $n=249$ ) and coactive (i.e., track and field/cross-country and tennis; $n=113$ ) team sports. Lastly, to address the third purpose of the study, stepwise multiple regressions were conducted to measure if coaches' and teammates' influence on basic psychological need satisfaction predicted participants' perceptions of, and satisfaction with, individual and team performance. 


\section{Results}

The response rate could not be determined because there was no indication for how many coaches forwarded the invitation including the survey link to their student-athletes. Therefore, any results from the current research are primarily exploratory and potentially not generalizable. Yet, the present findings begin to provide an understanding for the phenomena of interest and potentially highlight areas that would be worthy to explore in future research. A Confirmatory Factor Analysis using MPlus (Version 7.2) validated the underlying structure of the survey items and revealed acceptable model fit for the data $(R M S E A=.08,95 \%$ $C I[.077 ; .083], p<.001 ; C F I=.92)$. Reliability estimates for the entire sample revealed acceptable levels (i.e., above .70 based on the recommendations of DeVellis, 2012) for participants' ratings of the perceived influence of coaches on competence (6 items, Cronbach's $\alpha=.83$ ), autonomy ( 7 items, Cronbach's $\alpha$ $=.80)$, and relatedness ( 8 items, Cronbach's $\alpha=.90)$. Reliability estimates for teammates influence on competence (6 items, Cronbach's $\alpha=.77$ ), autonomy (7 items, Cronbach's $\alpha=.75$ ), and relatedness ( 8 items, Cronbach's $\alpha=.91$ ) were also good to excellent.

\section{Teammates' and Coaches' Influence on Basic Psychological Need Satisfaction}

Overall, participants' mean ratings were higher for their teammates than their coaches in satisfying their basic psychological needs (see Table 1). Paired sample $t$ test revealed statistically significant differences between participants' perceptions of coaches' and teammates' influence on the basic psychological needs of competence $[t(361)=3.70, p<.001,99 \% C I(.05 ; .31), d=0.17]$, autonomy $[t(361)=16.40$, $p<.001,99 \% C I(.79 ; 1.09), d=0.97]$, and relatedness $[t(361)=9.17, p<.001$, $99 \% C I(.42 ; .74), d=0.5]$. Teammates were perceived to have a significantly more positive influence (i.e., higher mean scores) on the satisfaction of all three basic psychological needs compared with coaches (see Table 1).

\section{Interactive and Coactive Team Sports and Basic Psychological Need Satisfaction}

A MANOVA revealed significant differences between interactive and coactive team sport participants' perceptions of coaches' and teammates' influence on basic psychological need satisfaction [Wilks's Lambda $=.87, F(1,362)=8.75, p<.001$, $d=.26]$. Univariate follow-up analysis revealed that participants in interactive team sports perceived their teammates to have a significantly more positive influence (i.e., higher mean scores) on relatedness $[F(1,362)=3.97, p<.05, d=.22]$ compared with participants in coactive sports. Differences between interactive and coactive team sport participants were not statistically significant for perceptions of teammates' influence on competence $[F(1,362)=1.16, p=.688, d=.05]$ and autonomy $[F(1,362)=.75, p=.388, d=.11]$. Furthermore, univariate follow-up analyses revealed that athletes in coactive team sports perceived their coaches to have a significantly more positive influence (i.e., higher mean scores) on competence $[F(1,362)=18.36, \mathrm{p}<.001, d=.54]$, autonomy $[F(1,362)=27.10, \mathrm{p}<$ 
Table 1 Teammates' and Coaches' Influence on Basic Psychological Need Satisfaction $(N=362)$

\begin{tabular}{|c|c|c|c|}
\hline & $\begin{array}{l}\text { Teammates' } \\
\text { Influence }\end{array}$ & $\begin{array}{l}\text { Coaches' } \\
\text { Influence }\end{array}$ & \\
\hline & $M(S D)$ & $M(S D)$ & $t(361)$ \\
\hline \multicolumn{4}{|l|}{ Total } \\
\hline Competence & $5.38(.960)$ & $5.20(1.19)$ & $3.70 *, 99 \%$ CI $(.05 ; .31)$ \\
\hline Autonomy & $5.40(.949)$ & $4.39(1.13)$ & $16.40 *, 99 \%$ CI $(.79 ; 1.09)$ \\
\hline Relatedness & $5.87(1.08)$ & $5.30(1.19)$ & $9.17 *, 99 \%$ CI $(.42 ; .74)$ \\
\hline \multicolumn{4}{|l|}{ Interactive } \\
\hline Competence & $5.35(.839)$ & $4.81(1.15)$ & \\
\hline Autonomy & $5.27(.830)$ & $3.95(1.11)$ & \\
\hline Relatedness & $6.04(.891)$ & $5.06(1.15)$ & \\
\hline \multicolumn{4}{|l|}{ Coactive } \\
\hline Competence & $5.40(1.01)$ & $5.40(1.03)$ & \\
\hline Autonomy & $5.37(1.00)$ & $4.59(1.08)$ & \\
\hline Relatedness & $5.80(1.15)$ & $5.40(1.19)$ & \\
\hline
\end{tabular}

Note. Possible range: 1 (not at all true) to 7 (very true). Higher means indicated higher levels of basic psychological need satisfaction. ${ }^{*} p<.001$

$.001, d=.58]$, and relatedness $[F(1,362)=6.47, p<.05, d=.29]$ compared with interactive team sport participants.

\section{Basic Psychological Need Satisfaction and Performance}

In the stepwise multiple regression models, coaches' influence on basic psychological need satisfaction (i.e., competence coach, autonomy coach, relatedness coach) and teammates' influence on basic psychological need satisfaction (i.e., competence teammate, autonomy teammate, relatedness teammate) were entered as the six predictor variables. The criterion variables for the four separate stepwise multiple regressions were perception of individual performance, satisfaction with individual performance, perception of team performance, and satisfaction with team performance. With each of the four stepwise regression analyses, bivariate correlations between independent variables and collinearity statistics (i.e., tolerance and variance-inflation factor) revealed that multicollinearity of independent variables was not a problem.

Perception of Individual Performance. The stepwise multiple regression revealed a one variable solution $[F(1,360)=30.38, p<.001]$ that accounted for $7.8 \%$ of the total variance in participants' perceptions of their individual performance $\left(R^{2}=.078\right)$. Competence coach $[\beta=.367, p<.001,95 \%$ CI $(.236, .498)]$ 
was the only significant predictor of athletes' perception of individual performance. As participants perceived greater fulfillment with how their coaches influenced their competence, their perception of individual performance also increased.

Satisfaction With Individual Performance. The stepwise multiple regression revealed a one variable solution $[F(1,360)=33.05, p<.001]$ that accounted for $8.4 \%$ of the total variance in participants' satisfaction with their individual performance $\left(R^{2}=.084\right)$. Competence coach $[\beta=.565, p<.001,95 \% C I(.371, .758)]$ was the only significant predictor of athletes' satisfaction with individual performance. As participants perceived greater fulfillment with how their coaches influenced their competence, their satisfaction with individual performance also increased.

Perception of Team Performance. The stepwise multiple regression revealed a one variable solution $[F(1,360)=28.08, p<.001]$ that accounted for $7.2 \%$ of the total variance in participants' perceptions of their team's performance $\left(R^{2}=\right.$ $.072)$. Relatedness coach $[\beta=.388, p<.001,95 \% C I(.244, .532)]$ was the only significant predictor of athletes' perception of team performance. As participants perceived greater fulfillment with how their coaches influenced their relatedness, their perception of the team's performance also increased.

Satisfaction With Team Performance. The stepwise multiple regression revealed a one variable solution $[F(1,360)=38.08, p<.001]$ that accounted for $9.6 \%$ of the total variance in participants' satisfaction with their team's performance $\left(R^{2}=\right.$ .096). Competence coach $[\beta=.576, p<.001,95 \% C I(.392, .759)]$ was the only significant predictor of athletes' satisfaction with team performance. As participants perceived greater fulfillment with how their coaches influenced their competence, their satisfaction with the team's performance also increased.

\section{Discussion}

The primary purpose of the current study was to explore if there was a difference between coaches' and teammates' impact on participants' perceptions of their basic psychological need satisfaction. In addition, the researchers assessed the contextual factor of sport type (i.e., interactive and coactive team sport) and its influence on individuals' perceptions of competence, autonomy, and relatedness. Finally, given the pressures to achieve outcome goals within the elite setting of NCAA Division I sport (Wrisberg \& Johnson, 2002) researchers explored whether coaches' and teammates' influence on athletes' need fulfillment affected participants' perception of, and satisfaction with, individual and team performance.

In general, the present findings show that both coaches and teammates had a positive effect on competence, autonomy, and relatedness (i.e., means scores were above the midpoint; see Table 1). Similarly, researchers have previously found that both coaches (e.g., Amorose \& Anderson-Butcher, 2007; Hollembeak \& Amorose, 2005) and peers (e.g., Joesaar et al., 2011; Kipp \& Weiss, 2013) play a role in nurturing athletes' need fulfillment. However, to the authors' knowledge the current study is the first to directly compare the magnitude of need fulfillment between coaches and teammates. Specifically, participants in the current study reported significantly greater satisfaction from teammates for all three basic psychological needs compared with coaches, with autonomy producing the largest 
effect size $(d=0.97)$. While participants were not asked to report the reasons why teammates provided greater basic psychological need satisfaction, the literature in self-determination theory may help to understand what may contribute to such a positive influence from teammates.

For example, the influence of teammates on athletes' basic psychological need satisfaction appears to be primarily determined by interpersonal relationships and social interactions (Keegan et al., 2010). Researchers have found that the quality of friendship between peers is associated with perceptions of competence, autonomy, and relatedness (Blanchard et al., 2009; Kipp \& Weiss, 2013). Hassell, Sabiston, and Bloom (2011) previously indicated that athletes often struggle to build meaningful relationships with nonathletes as those individuals cannot identify with their training, commitment, and competition. Therefore, it appears reasonable to presume that they likely try to develop positive relationships and friendships with teammates that potentially go beyond the athletic setting. This assumption is supported by Evans et al. (2013) who reported that athletes often refer to teammates as their closest friends. Similarly, in a study with collegiate swimmers Raabe, Zakrajsek, and Readdy (2016) found that participants' spent most of their time outside the pool with teammates and described them as family. The current finding is important as Vallerand (1997) suggested that there is the potential for reciprocal effects on need fulfillment between different contexts. This means that positive peer interactions and relationships outside the athletic environment can nurture perceptions of competence, autonomy, and relatedness in sport. Such need fulfillment outside of sport has been shown to enhance adjustment (Milyavskaya et al., 2009) and prevent athlete burnout (Perreault, Gaudreau, Lapointe, \& Lacroix, 2007) in sport.

Coaches and the coach-athlete relationship have also been suggested to play a meaningful role in athletes' sport experience (Chelladurai, 1993; Jowett \& Cockerill, 2003; Mageau \& Vallerand, 2003; Poczwardowski et al., 2002; Pelletier et al., 2001). Thus, given their central role within athletics, it would be helpful to conduct future research to gain an understanding of why participants' rated coaches' influence on their basic psychological need satisfaction as lower than their teammates. In part, this can likely be attributed to coaches' interpersonal style, which can either be controlling and characterized by a highly-directive manner or autonomy-supportive and empower athletes by leaving room for their input (Vallerand \& Losier, 1999). Numerous researchers (e.g., Amorose \& Anderson-Butcher, 2007; Hollembeak $\&$ Amorose, 2005) have found that athletes who evaluated their coaches to be autonomy-supportive as opposed to controlling reported higher levels of competence, autonomy, and relatedness. While coaching behaviors were not measured in this study the results indicate that teammates might demonstrate less controlling behaviors than coaches in NCAA Division I athletics. Overall, although caution must be taken with interpreting the current findings, the results do suggest that athletes' interactions and relationships with their teammates and coaches may differ with respect to need fulfillment.

The current study's second consideration was an exploration of the influence of different sport type on athletes' perceived need fulfillment. Results indicate a statistically significant difference in teammates' and coaches' influence on basic psychological need satisfaction between individuals participating in interactive and coactive team sports. Similar to the findings of Stults-Kolehmainen et al. (2013) 
the present investigation revealed that teammates' influence on relatedness was more positive (i.e., higher mean scores) for athletes competing in interactive sports compared with those in coactive sports. In order for individuals to experience high perceptions of relatedness they need to feel securely connected with others and see themselves as valuable members of the group (Deci \& Ryan, 2000). In this context, groups have been defined as:

Two or more individuals who possess a common identity, have common goals and objectives, share a common fate, exhibit structured patterns of interaction and modes of communication, hold common perceptions about group structure, are personally and instrumentally interdependent, reciprocate interpersonal attraction, and consider themselves to be a group (Carron \& Hausenblas, 1998, pp. 13-14).

Thus, having a strong interdependence not only characterizes a group but also aligns with individuals' satisfaction of their need for relatedness. It is such interdependence that unites teammates and enhances their relationships (Evans et al., 2013). The current results propose that interactive team sports, which require members to coordinate their actions to achieve performance outcomes (Weinberg \& Gould, 2011), nurture such interdependence and, consequently, individual members' perceptions of relatedness. While athletes on coactive sport teams strive toward a common goal they compete individually (Weinberg \& Gould, 2011). Therefore, these athletes determine the degree to which they choose to work collaboratively rather than being a sole aggregate of individuals training together. Hence, coactive team sport members have a varying level of interdependence as they can typically choose to function independently (Evans et al., 2013). It is likely that the satisfaction of the need for relatedness was lower for the current sample of coactive participants as a result of lower levels of interdependence compared with those on interactive team sports.

Simultaneously, the present findings show that individuals in coactive team sports perceived their coaches to have a significantly more positive impact (i.e., higher mean scores) on their perceptions of competence, autonomy, and relatedness compared with interactive team sport participants. These results suggested that coaches might have contrasting interactions, styles, and relationships based on contextual factors such as sport type. While their work was not conducted utilizing a self-determination theory perspective, previous researchers (Bloom, Durand-Bush, Schinke, \& Salmela, 1998; Jowett, Paull, \& Pensgaard, 2005) have argued that coaches in coactive sports may focus more on developing each individual athlete while coaches in interactive team sports may be more concerned with developing the team as a whole. Therefore, coaches in interactive team sports predominantly work with athletes as part of a group rather than on a one-on-one basis. This can potentially cause athletes to develop a different perspective of the coach-athlete relationship. For example, Rhind, Jowett, and Yang (2012) compared athletes' perceptions of the coach-athlete relationship based on sport type and found that in contrast to interactive sport participants athletes in coactive sports felt closer and more committed to their coach and that their coach offered more trust, respect, and appreciation. It appears that the difference in sport type also affects how needfulfilling athletes perceive their coaches to be. Consequently, the current findings 
call for research within self-determination theory to further examine the role of sport type as an antecedent for coaching behaviors.

Finally, step-wise regression analyses revealed that it was coaches' influence on basic psychological need satisfaction, in particular the need of competence, which significantly predicted performance measures. This finding offers both practical and theoretical insights. First, it supports the importance of the coach-athlete relationship (Mageau \& Vallerand, 2003). While teammates had a more positive influence on athletes' need fulfillment it was the coaching staff that affected individuals' perceptions of, and satisfaction with, performance. Specifically, it appeared that the more athletes' perceived their coaches to enhance their competence the better they subjectively evaluated their performance. According to Deci and Ryan (2000), this competence, helps humans to adjust to new challenges in changing contexts and to use learned skills or continue to develop their ability. It appears reasonable to suggest that these are all antecedents to successful performance in athletic competition. While the step-wise regression results only explained a small amount of variance in performance ratings (i.e., between $7.2 \%$ and 9.6\%), such levels may offer practical worth within the NCAA Division I sport context. Readdy et al. (2014) explored the impact of an external reward program on NCAA Division I football players' motivation and performance. The authors discussed that such a program might improve athletes' motivation and performance by $5 \%$ at best, yet the participating coach highlighted that in the context of elite athletics even small improvements could mean the difference between a win and a loss.

From a theoretical perspective previous researchers have investigated the effects of performance on need fulfillment (Gillet et al., 2009); however, to the authors' knowledge this is the first study that directly assessed the influence of basic psychological need satisfaction on perceptions of and satisfaction with performance. In comparing the current findings with those of Gillet et al. (2009) it appears likely that a bidirectional relationship may exist between need fulfillment and performance, which expands on present knowledge in the field of self-determination theory (Deci \& Ryan, 2000) and should be explored further in additional studies.

\section{Practical Implications}

The current findings offer valuable information for coaches and administrators that can help to nurture social interactions which foster athletes basic psychological need satisfaction and, therefore, contribute to their optimal social functioning, well-being, and self-development. Overall, both coaches and teammates had a positive effect on athletes' perceptions of competence, autonomy, and relatedness. However, teammates had a significantly more positive influence on athletes' need fulfillment. This suggests that there is room for coaches to improve their interactions with athletes, especially since the present results indicate that it is the need fulfillment from coaches_-in particular the need for competence-that influence athletes' perceptions of performance. Hence, it appears valuable for coaches to take a vested interest in adopting an autonomy-supportive interpersonal style, in which "an individual in a position of authority [coach] takes the other's [athlete's] perspective, acknowledges the other's feelings, and provides the other with pertinent information and opportunities for choice, while minimizing the use of pressures and demands" (Black \& Deci, 2000, p. 742). This cannot only help to cultivate 
the various benefits associated with fostering athletes' basic psychological need satisfaction (e.g., higher well-being; Gagne, 2003) but also appears to have a positive influence on athletes' performance. For administrators it seems important to support coaches in their efforts by providing them with opportunities for professional development.

Furthermore, due to the potential reciprocal effect on need fulfillment between different contexts it seems valuable for coaches to demonstrate a genuine care for athletes' lives outside of the sport environment. More specifically, it is difficult for athletes to trust coaches who do not show an interest in them on a personal level or can have a conversation about something nonsport related (Bennie \& O'Connor, 2012). The results of this study also suggest that coaches of interactive teams may want to consider ways that help them nurture individual relationships with each member of their team. When working in the team setting it is important for coaches to focus on both the overall group and the individual athlete. That is, coaches should find ways to foster a collaborative and interdependent climate among their team, while simultaneously finding time for one-on-one interactions with their athletes and providing them with individualized performance feedback. Ways to nurture relatedness (e.g., creating opportunities for interdependence) appears to be a particularly important consideration for coaches of coactive team sports. In their qualitative study, Raabe and colleagues (2016) provide a starting point in this endeavor by offering multiple strategies that can help to cultivate positive teammate interactions and enhance athletes' basic psychological need satisfaction. For example, athletes should be encouraged to establish their identity, rules, expectations, goals, and purpose collectively as a team and revisit them regularly throughout the year.

\section{Limitations}

While this endeavor was able to fill gaps within the self-determination theory literature there were also limitations that should be addressed in future research. These limitations were primarily related to the sample. First, the inability to determine the response rate decreases the ability to generalize findings to the overall population. Second, student-athletes who chose to complete the survey may hold different perceptions about their coaches' and teammates' influence on need fulfillment than athletes who did not complete the survey, also limiting the generalizability of the results. Third, the research was delimited to a sample of four sports (i.e., track and field/cross country, soccer, basketball, and tennis). Although these sports did present diversity between interactive and coactive sports, further examination with additional sports could expand on current conclusions. Fourth, competitive success has the potential to influence basic psychological need satisfaction (Vallerand \& Losier, 1999). Hence, the difference between athletes in starting and reserve roles, which was not assessed, could have impacted participants' perceptions of their coaches and teammates. Fifth, the results of the current study were based on participants' perceptions of their performance. Thus, a similar investigation utilizing objective performance measures would add to the strength and generalizability of the conclusions. Sixth, the cross-sectional design limits the ability to demonstrate causalities between basic psychological need satisfaction and performance measures. 


\section{Conclusions}

Overall, while exploratory in nature, the current study expanded on previous endeavors and found varying effects on athletes' basic psychological need satisfaction from coaches and teammates. While peers had a significantly more positive influence on individuals' perceptions of competence, autonomy, and relatedness it was the need fulfillment from coaches that predicted athletes' perceptions of, and satisfaction with, performance. In addition, there were significant differences in teammates' and coaches' impact on basic psychological need satisfaction between individuals participating in interactive and coactive team sports. While teammates' influence on relatedness was more positive for athletes competing in interactive sports compared with those in coactive sports, individuals in coactive team sports perceived their coaches to have a significantly more positive impact on their fulfillment of all three basic psychological needs compared with interactive team sport participants.

\section{References}

Amorose, J.A., \& Anderson-Butcher, D. (2007). Autonomy-supportive coaching and self- determined motivation in high school and college-athletes: A test of selfdetermination theory. Psychology of Sport and Exercise, 8, 654-670. doi:10.1016/j. psychsport.2006.11.003

Baard, P.P., Deci, E.L., \& Ryan, R.M. (2004). Intrinsic need satisfaction: A motivational basis of performance and well-being in two work settings. Journal of Applied Social Psychology, 4, 2045-2068.

Bennie, A., \& O'Connor, D. (2012). Coach-athlete relationships: A qualitative study of professional sport teams in Australia. International Journal of Sport and Health Science, 10, 58-64. doi:10.5432/ijshs.201208

Black, A.E., \& Deci, E.L. (2000). The effects of instructors' autonomy support and students' autonomous motivation on learning organic chemistry: A self-determination theory perspective. Science Education, 84, 740-756. doi:10.1002/1098237X(200011)84:6<740::AID-SCE4>3.0.CO;2-3

Blanchard, C.M., Amiot, C.E., Perreault, S., Vallerand, R.J., \& Provencher, P. (2009). Cohesiveness, coach's interpersonal style and psychological needs: Their effects on selfdetermination and athletes' subjective well-being. Psychology of Sport and Exercise, 10, 545-551. doi:10.1016/j.psychsport.2009.02.005

Bloom, G.A., Durand-Bush, N., Schinke, R.J., \& Salmela, J.H. (1998). The importance of mentoring in the development of coaches and athletes. International Journal of Sport Psychology, 29, 267-281.

Carron, A.V., \& Hausenblas, H.A. (1998). Group dynamics in sport (2nd ed.). Morgantown, WV: Fitness Information Technology.

Chelladurai, P. (1993). Leadership. In R.N. Singer, M. Murphey, \& L.K. Tennant (Eds.), Handbook of research on sport psychology (pp. 647-671). New York, NY: Macmillan.

Deci, E.L., Connell, J.P., \& Ryan, R.M. (1989). Self-determination in a work organization. The Journal of Applied Psychology, 74, 580-590. doi:10.1037/0021-9010.74.4.580

Deci, E.L., \& Ryan, R.M. (2000). The "what" and "why" of goal pursuits: Human needs and the self-determination of behavior. Psychological Inquiry, 11, 227-268. doi:10.1207/ S15327965PLI1104_01

DeVellis, R.F. (2012). Scale development: Theory and applications. Thousand Oaks, CA: Sage. 
Evans, B., Eys, M., \& Wolf, S. (2013). Exploring the nature of interpersonal influence in elite individual sport teams. Journal of Applied Sport Psychology, 25, 448-462. doi:10 $.1080 / 10413200.2012 .752769$

Froyen, A.F., \& Pensgaard, A.M. (2014). Antecedents of need fulfillment among elite athletes and coaches: A qualitative approach. Journal of Applied Sport Sciences, 26, $26-41$.

Gagne, M. (2003). Autonomy support and need satisfaction in the motivation and well-being of gymnasts. Journal of Applied Sport Psychology, 15, 372-390. doi:10.1080/714044203

Gillet, N., Berjot, S., \& Gobance, L. (2009). A motivational model of performance in the sport domain. European Journal of Sport Science, 9, 151-158. doi:10.1080/17461390902736793

Gould, D., Dieffenbach, K., \& Moffett, A. (2002). Psychological characteristics and their development in Olympic champions. Journal of Applied Sport Psychology, 14, 172-204. doi:10.1080/10413200290103482

Hassell, K., Sabiston, C.M., \& Bloom, G.A. (2011). Exploring multiple dimensions of social support among elite female adolescent swimmers. International Journal of Sport Psychology, 41, 340-359.

Hollembeak, J., \& Amorose, A.J. (2005). Perceived coaching behaviors and college athletes' intrinsic motivation: A test of self-determination theory. Journal of Applied Sport Psychology, 17, 20-36. doi:10.1080/10413200590907540

Joesaar, H., Hein, V., \& Hagger, M.S. (2011). Peer influence on young athletes' need satisfaction, intrinsic motivation and persistence in sport: A 12-month prospective study. Psychology of Sport and Exercise, 12, 500-508. doi:10.1016/j.psychsport.2011.04.005

Jowett, S., \& Cockerill, I.M. (2003). Olympic medallists' perspective of the athlete-coach relationship. Psychology of Sport and Exercise, 4, 313-331. doi:10.1016/S14690292(02)00011-0

Jowett, S., Paull, G., \& Pensgaard, A.M. (2005). Coach-athlete relationship. In J. Taylor \& G.S. Wilson (Eds.), Applying sport psychology in sport (pp. 3-14). Champaign, IL: Human Kinetics.

Keegan, R., Spray, C., Harwood, C., \& Lavallee, D. (2010). The motivational atmosphere in youth sport: Coach, parent, and peer influences on motivation in specializing sport participants. Journal of Applied Sport Psychology, 22, 87-105. doi:10.1080/10413200903421267

Kipp, L.E., \& Weiss, M.R. (2013). Social influences, psychological need satisfaction, and well-being among female adolescent gymnasts. Sport, Exercise, and Performance Psychology, 2, 62-75. doi:10.1037/a0030236

Long, N., Readdy, T., \& Raabe, J. (2014). What motivates firefighters to exercise? A mixedmethods investigation of self-determination theory constructs and exercise behavior. Sport, Exercise, and Performance Psychology, 3, 203-218. doi:10.1037/spy0000012

Mack, D.E., Wilson, P.M., Oster, K.G., Kowalski, K.C., Crocker, P.R.E., \& Sylvester, B.D. (2011). Well-being in volleyball players: Examining the contributions of independent and balanced psychological need satisfaction. Psychology of Sport and Exercise, 12, 533-539. doi:10.1016/j.psychsport.2011.05.006

Mageau, G.A., \& Vallerand, R.J. (2003). The coach-athlete relationship: A motivational model. Journal of Sports Sciences, 21, 883-904. PubMed doi:10.1080/0264041031000140374

Milyavskaya, M., Gingras, I., Mageau, M., Koestner, R., Gagnon, H., Fang, J., \& Boiche, J. (2009). Balance across contexts: Importance of balanced needs satisfaction across various life domains. Personality and Social Psychology Bulletin, 35, 1031-1045. PubMed doi:10.1177/0146167209337036

National Collegiate Athletic Association. (2014). Division I 20/8-hour rule materials. Retrieved November 11, 2014 from: http://www.ncaa.org/division-i-20/8-hour-rule-materials

Pelletier, L.G., Fortier, M.S., Vallerand, R.J., \& Briere, N.M. (2001). Associations among perceived autonomy support, forms of self-regulation, and persistence: A prospective study. Motivation and Emotion, 25, 279-306. doi:10.1023/A:1014805132406 
Perreault, S., Gaudreau, P., Lapointe, M-C., \& Lacroix, C. (2007). Does it take three to tango? Psychological need satisfaction and athlete burnout. International Journal of Sport Psychology, 38, 437-450.

Poczwardowski, A., Barot, J.E., \& Henschen, K.P. (2002). The athlete and coach: Their relationship and its meaning: Results of an interpretative study. International Journal of Sport Psychology, 33, 116-140.

Podlog, L., \& Dionigi, R. (2010). Coach strategies for addressing psychological challenges during the return to sport from injury. Journal of Sports Sciences, 28, 1-12. PubMed doi:10.1080/02640414.2010.487873

Raabe, J., Zakrajsek, R.A., \& Readdy, T. (2016). Teammate influence on collegiate swimmers' basic psychological need satisfaction: A qualitative perspective. Journal of Intercollegiate Sport, 9, 27-49. doi:10.1123/jis.2015-0016

Readdy, T., Raabe, J., \& Harding, J. (2014). Student-athlete perceptions of an extrinsic reward system: An exploration of self-determination theory in the context of college football. Journal of Applied Sport Psychology, 26, 157-171. doi:10.1080/10413200.2013.816801

Rhind, D.J.A., Jowett, S., \& Yang, S.X. (2012). A comparison of athletes' perceptions of the coach-athlete relationship in team and individual sports. Journal of Sport Behavior, $35,433-452$.

Street, J.M. (1999). Self-Efficacy: A Tool for Providing Effective Support Services for Student-Athletes. In S. Robinson (Ed.), Gaining the Competitive Edge: Enriching the Collegiate Experience of the New Student-Athlete. Columbia, SC: National Resource Center for the First Year Experience and Students in Transition, University of South Carolina.

Stults-Kolehmainen, M.A., Gilson, T.A., \& Abolt, C.J. (2013). Feelings of acceptance and intimacy among teammates predict motivation in intercollegiate sport. Journal of Sport Behavior, 36, 306-326.

Vallerand, R.J. (1997). Toward a hierarchical model of intrinsic and extrinsic motivation. In M.P. Zanna (Ed.), Advances in experimental social psychology (pp. 271-360). New York, NY: Academic Press. doi:10.1016/S0065-2601(08)60019-2

Vallerand, R.J., \& Losier, G.F. (1999). An integrative analysis of intrinsic and extrinsic motivation in sport. Journal of Applied Sport Psychology, 11, 142-169. doi:10.1080/10413209908402956

Watt, S.K., \& Moore, J.L. (2001). Who are student athletes? New Directions for Student Services, 93, 7-18. doi:10.1002/ss.1

Weinberg, R.S., \& Gould, D. (2011). Group cohesion. Foundations of sport and exercise psychology (pp. 179-202). Champaign, IL: Human Kinetics.

Wolverton, B. (2008). Athletes' hours renew debate over college sports. The Chronicle of Higher Education, 54, 1.

Wrisberg, C.A., \& Johnson, M.S. (2002). Quality of life. In M. Kellmann (Ed.), Enhancing recovery: Preventing underperformance in athletes (pp. 253-267). Champaign, IL: Human Kinetics.

Zakrajsek, R.A., Abildso, C.G., Hurst, J.R., \& Watson, J.C. (2007). The relationship among coaches' and athletes' perceptions of coaching staff cohesion, team cohesion, and performance. Athletic Insight, 9, 1-14. 